\title{
Perceptions Of Environmental Sustainability
}

\author{
Gwendolen B. White, Ball State University \\ Mandy J. Cleveland, Ball State University \\ Michael J. White, Ball State University
}

\begin{abstract}
This study examines attitudes toward environmental sustainability among college students. The new area of "sustainability reporting" identifies business practices that are associated with environmental and social costs. When these costs are known, managers can take steps to reduce them, resulting in improved profit and lessened environmental impact. Many believe it has great potential to change the way business is practiced. Responses were analyzed using multidimensional scaling analyses, permitting comparison of the perceived similarity and dissimilarity of "sustainability" to other environmentally significant terms. Results from these and semantic differential analyses showed that sustainability is perceived positively, although it is not perceived as especially dynamic nor is it associated with sound economics. Suggestions for educating students and the public about sustainability reporting are offered.
\end{abstract}

Keywords: Sustainability accounting, environment, semantic differential, multi-dimension scaling

What is sustainability? ... Understanding sustainability requires an awareness of how everything we do, everything we take, everything we make and everything we waste affects nature's balance, and how our actions will ultimately affect our children and the children of all species. ... Each choice we make has a 'cost.' True cost is a combination of the economic, social and environmental costs set against the offsetting benefits associated with each choice that we make. Interface, Inc. (2007)

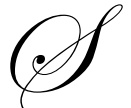

ustainability reporting by corporations is a growing trend. It is recognized as a means for companies to communicate how they operate more efficiently and responsibly within the physical and social environments while still remaining profitable. As a case in point, Interface, Inc., an international commercial carpet and fabric manufacturer has committed to sustainability by substantially reducing their impact on the environment and at the same time enhancing shareholder value. This commitment was a major one because the carpet industry uses large amounts of petroleum and other raw materials. In 1994, Ray Anderson, CEO of Interface, recognized that his company had been operating for 21 years without conscious consideration of the company's impact on the environment other than to be in compliance with existing environmental laws and regulations. Since that time, Anderson has redefined Interface's goal to be a "restorative enterprise," one that gives back more than it takes from the earth.

Interface has since been evaluating their progress toward sustainability with a variety of metrics. For example, since 1996 the company has avoided $\$ 336 \mathrm{M}$ in costs from their concerted waste elimination efforts. Their waste elimination involves a variety of activities. For example, they reclaim used carpet to recycle the materials as raw materials for new production. Over the last 10 years, the company has reduced energy and water use in the production of their products. Concerted efforts are under way to use renewable energy sources for production. Solar panels, energy from wind, and landfill gases are being used to power several of their plants. Not only has their mission to become a sustainable company reduced their costs, but also it has enhanced the development of new products that are free of fossil fuels. They are developing bio-based fibers for carpet and upholstery that can be safely composted after it is put into a landfill. By measuring and publishing their progress, Interface showcases their responsible behavior and enhances their operations.

Although separate environmental reports began in the early 1990s, its history is connected to corporate misdeeds that occurred in the 1980s. Disasters perpetrated by Union Carbide and Exxon are prominent examples of 
damage caused by corporate misbehavior in that decade. In 1984, a deadly gas (methyl isocyanate) leak and explosion at Union Carbide's pesticide plant in Bhopal, India, initially killed 3,000 people and injured thousands. In addition, the area around the plant was seriously contaminated. When the oil tanker Exxon Valdez went aground on Prince William Sound, Alaska, and spilled approximately 11 million gallons of crude oil, the devastation highlighted how much environmental and social damage one company could do. As a result, investors began to demand more corporate accountability.

In addition to investors, parties who affect and can be affected by a company's actions (i.e., "stakeholders") are now a growing force and have been demanding more environmental accountability from corporations. Environmental reports are an example of non-financial reporting that supplement information provided by traditional financial statements that are prepared in accordance with Generally Accepted Accounting Principles (GAAP). These environmental reports provide information about a business' activities that affect the environment to both external and internal users.

Although the U.S. Securities and Exchange Commission (SEC) requires that independent CPAs audit the financial statements of publicly held companies, U.S. law does not require that companies prepare and publish environmental reports in the same fashion. Furthermore, there are no generally accepted environmental reporting standards to guide companies. Even without such standards, many companies voluntarily prepare and publish reports to help measure their environmental impact and improve performance in specific areas. For example, CocaCola publishes environmental reports to improve their environmental performance in three major areas - water usage, energy usage, and recycling (Coca-Cola, 2005). Publishing these reports is a means of communicating environmental progress to internal managers and to stakeholders.

It should be acknowledged that many companies prepare such reports because of a sincere desire to "do good." Nonetheless, because most of these reports are neither audited nor certified by independent third parties their accuracy may be suspect. Further, because the reports are often used as a public relations tool by companies to promote their environmentally friendly activities, the motives of some corporations are questionable. Indeed, the lack of generally accepted reporting standards and outside verification of environmental reports has lead to their characterization as mere "greenwashing" (Laufer, 2003).

While environmental issues dominated non-financial reporting in the 1990s, numerous corporate scandals involving poor working conditions, child labor, and corporate fraud have created a demand for reports on corporate responsibility. Corporate responsibility is broadly defined and encompasses areas such as corporate governance, ethics, and workers' rights. The financial scandals at WorldCom and Enron illustrate how weaknesses in corporate governance contributed to the opportunities for fraudulent activities by executives and to financial ruin for many stakeholders. In a similar manner, the revelation of exploitative child labor and abysmal working conditions in Nike's and Addidas' overseas factories brought pressure on other companies to monitor and report on their labor practices.

In response to these demands and in order to capture their progress in areas of corporate governance, workers' rights, and environmentally sustainable practices, many companies are preparing and publishing sustainability reports. According to the KPMG International Survey of Corporate Responsibility Reporting 2005, nearly $70 \%$ of the top 250 companies of the Global Fortune 500 companies publish sustainability reports (KPMG, 2005).

Although there are no generally accepted reporting standards, sustainability reports typically include environmental, social, and economic issues not represented in the financial statements. Willem Bröcker, managing global partner of PricewaterhouseCoopers, states, "For many corporations, sustainability is becoming not just 'a nice thing to do' but a core requirement, enabling them to increase their value and sustain profitability in the long term" (PricewaterhouseCoopers, 2004). In 2002, 81 percent of the senior executives in large U.S.-based businesses reported that sustainability practices will be essential or very important to their company's strategic mission over the next two years (PricewaterhouseCoopers, 2002). Social and environmental sustainability practices influence not only companies' strategic missions, but also their financial success. Based on the increased number of sustainability 
reports being published, it appears that the business community is placing increasingly more importance on sustainability reporting. Despite the increasing numbers of large companies adopting sustainability reporting, many more have not. And from a global perspective, only a relatively small number of companies (approximately 1500) publish sustainability reports (Corporate Register, 2004).

As every public relations expert knows, for an idea to be accepted by an audience it must be perceived as congenial to the recipient's accepted values. For example, rather than call their product "sewage sludge," the water treatment industry now calls it by the less tainted term, "biosolids." Regardless of what it is called, it is a useful product. But by minimizing its origins, it is more acceptable to the public (Biosolids.com, 2007). As another example, during her time in the Bush administration the communications expert Karen Hughes sought to portray her boss as "moderate, reasonable, and thoughtful," especially regarding domestic policy. She did so by emphasizing soft, reassuring language such as "employers" rather than "business," "moms and dads" instead of "parents," and "tax relief" in place of "tax cuts" (Lizza, 2003). "Relief" is, of course, always positive, while "cutting" may not be. Further, according to one of Hughes' speechwriters, David Frum, "above all things, she hated the word 'but,' a word that suggests harsh choices, conflict, even confrontation (p. 19, cited in Fritz, Keefer, \& Nyhan, 2004).”

For sustainability reporting to be widely adopted, it must of course deliver genuine and incontestable benefits. Effective communication of these benefits will be crucial to its success. But also, at least in the current, early stages of adoption, it must be presented and defined in such a way that it is perceived positively. In particular, how is the word "sustainability" perceived? Is it the best term to use in the introduction of this new form of reporting?

Some may view sustainability reporting as an extension of environmental reporting. And it must be said that business leaders have not always viewed environmentalism positively. Many have seen environmental controls as representing high immediate costs to their individual company with only limited direct benefits (cf. Hardin, 1968). Although pursuing the public good is fine, companies ask "What is in it for us?" The sustainability consultant can reply that there is a great deal that could be in it for you. Reducing your waste can increase your profits, providing better working conditions for your workers can reduce your turnover costs, and minimizing your environmental footprint can generate positive attitudes toward your company. But if the term "sustainability" is seen as anti-business, sustainability reporting may not succeed as a valuable business tool. This study seeks to answer the question of how is the word "sustainability" perceived.

Two approaches were used. The first and more general approach used the semantic differential to place sustainability and five other environment and business-related concepts in a three-dimensional "semantic space." This semantic space is defined by three factor-analytically derived dimensions (i.e., evaluation, potency, and activity), which can be used to characterize the semantic meaning attached to an object or concept. The semantic differential has been widely used across different cultures and languages and has produced reliable results (cf., Osgood, May, \& Miron, 1975; White \& Li, 1991). The second strategy sought to characterize sustainability and the other five concepts using six terms and phrases specific to sustainability reporting (Global Reporting Initiative, 2007). The correlations for the responses to each of these six terms were then calculated and used as indices of similarity in a multi-dimensional scaling (MDS) analysis. Using MDS, a visual and statistical representation of the similarity or semantic distance between objects can be constructed.

\section{METHOD}

\section{Participants}

A total of 161 university students voluntarily participated. The mean age was $22.1(\mathrm{SD}=4.4)$. There were 61 men and 100 women. Students reported their ethnicity as follows: Caucasian American (81.8\%), African American (10.7\%), Asian American (2.5\%), Hispanic American (1.9\%), and Other (3.1\%). Students earned extra credit or research participation points according to plans approved by their respective course instructors. 


\section{Materials}

Target Concepts. In addition to "sustainability," five additional target concepts were used in this study. Two of them, "conservation" and "environmentalism," were selected as near synonyms to sustainability. Two others, "pollution" and "eco-terrorism," were thought to be antonyms to sustainability. "Eco-terrorism" most commonly refers to groups that espouse violence to protect the environment (e.g., "Earth Liberation Front" and "Earth First"; Wikipedia, 2007). Finally, "industrial development" was selected as representative of traditional industrial activity.

Semantic Differential Items. The overall order for the six target concepts was determined by random selection. Ten semantic differential adjective pairs followed each concept with the polarity of the adjective pair having been randomly determined. The computer-based survey program used to collect responses randomly generated the order of these pairs for each concept and for each participant. Respondents made their choices using seven-point response scales with the adjective pairs serving as the end points. Osgood et al.'s (1975) instructions were followed for the final recoding of data; the highest value was +3 , with the lowest being -3 . Four adjective pairs defined the "Evaluation" dimension: Bad-Good, Awful-Nice, Unhelpful-Helpful, and Foolish-Wise. After recoding adjective pairs with reversed polarity such that higher scores had a positive meaning, the mean was taken of the four items to calculate an Evaluation score. Potency was calculated as the (polarity corrected) mean response to Shallow-Deep, Weak-Strong, and Powerless-Powerful. The Activity dimension was similarly defined using SlowFast, Passive-Active, and Old-Young.

Sustainability Reporting Items. The same six target concepts (e.g., sustainability and pollution) were rated in the response to the following phrases: (Target concept) is ethical, ... is socially responsible, ... enhances opportunities for future generations, $\ldots$ is economically progressive, ... is economically sound, and ... is environmentally conscious. Respondents used a seven-point rating scale with "Not at all" and "Extremely" serving as the end points. As with the semantic differential items, the polarity of half of the rating scales was randomly reversed during administration. In order that data might all be presented using the same directionality, these were subsequently reverse scored so that a high score had a positive meaning. The computer program randomly determined the order of phrases for each target concept and respondent.

\section{Apparatus And Procedure}

Participants made their responses using an internet-based survey program on computers located in one of two campus computer laboratories at a time of their choosing (Fortriede, 2006). Student responses were anonymous with no records kept of their identity. The program first included an informed consent statement, followed by the semantic differential and sustainability accounting items. The last section of the survey included questions about environmentally related behaviors (not discussed in this manuscript) and questions about the respondent's age, gender, and the like. Upon completion of the survey, the lab assistant gave students a participation receipt, which they then gave to their instructors in order to receive research participation credit.

\section{RESULTS}

\section{Semantic Differential}

Responses for men and women were first contrasted with gender serving as the between-subjects factor and the semantic differential measures as the dependent variables. Because the comparison was not significant (Pillai's trace, $F(18,126)=1.19, p=.23)$, data are combined across gender. Note that after listwise deletion of incomplete responses the final sample size for this and other analysis is 146 (56 men, 89 women).

As may be seen in Table 1, conservation (2.13) and environmentalism (1.99) receive the highest scores for evaluation (i.e., "goodness") with sustainability not far behind (1.50). Industrial development is slightly positive (.56), while both eco-terrorism (-1.78) and pollution (-2.35) receive negative scores. In contrast, the target having the most potency or "aggressiveness" was pollution (1.29). Little variability was observed in other targets on this 
dimension. There was a similar lack of variability on the activity or "doing" dimension. Here the highest scoring target for activity was industrial development (.61). The three positive targets on evaluation were either close to neutral or even negative on this dimension (i.e., conservation: .06, environmentalism: .26, and sustainability: -.03). One must conclude that the respondents see the environmentally oriented targets as good, but lacking in potency or power and having little activity or dynamism. They are thus good, but static. By contrast, industrial development is only somewhat good, has little potency, but is, relative to other targets, the most active and dynamic. Responses to pollution indicate that it is bad (-2.35), lacks activity (.30), and yet is the most potent of all the targets (1.29). Finally, eco-terrorism, like pollution, is bad (-1.78). Yet it is also not especially potent (.73), even though it is the second highest rated target for activity (.43).

\section{Sustainability Reporting Items}

Six MDS analyses and associated cluster plots were conducted using the items relevant to sustainability reporting. In each case, the correlation matrix of responses to the target word (e.g., sustainability) was first calculated. This matrix was treated as the measure of similarity or proximity in the analysis. It was then used in a Euclidean distance model MDS analysis of individual variables using two dimensions. Up to 30 iterations were permitted for fitting the model. The analysis for "ethical" resulting in a stress value of .02 (where 0.0 is optimal) and $R^{2}$ value (i.e., the proportion of variance in the scaled data accounted for by corresponding distances) was .99. The data are thus well described by this analysis and may be viewed in Figure 1.

As may be seen, the first dimension appears to be an evaluative dimension with environmentally "good" target ideas (e.g., conservation) being on the left and "bad" targets being (e.g., pollution) on the right. Dimension 2 is more difficult to characterize. Sustainability is low on this dimension where conservation, environmentalism, and industrial development are high. To further enhance interpretation, a hierarchical cluster analysis of these target items was conducted. Although defining clusters is always partly subjective, as is interpreting what the underlying dimensions mean, four clusters appear to best represent the items. The overall distance coefficient was 31.4, with a much greater coefficient at the next stage (Aldenderfer \& Blashfield, 1984). It should be noted that nearly as good a fit could be obtained by combining sustainability with the conservation and environmentalism cluster. The fourcluster solution, however, suggests that conservation and environmentalism are equivalent for ethicality. Ecoterrorism and pollution are also equivalent on ethicality (or perhaps lack of it). Industrial development falls midway to these extremes. In the four-cluster solution sustainability is not like other terms, but if a three-cluster solution were used it would be equivalent to conservation and environmentalism.

Figure 2 contains the results for the MDS analysis of "socially responsible." As with the ethics analysis, a four-cluster solution was obtained (distance coefficient $=29.3$ ). Stress was once again low $(.05)$ and $R^{2}$ was high (.99). This time, however, conservation, environmentalism, and sustainability share the same cluster on the "good" side of Dimension 1. Although eco-terrorism and pollution are on the "bad" side of Dimension 1, they are very different on Dimension 2. Industrial development occupies its own cluster and is midway between the others. Dimension 2 appears to capture something like the semantic differential Activity factor, with terrorism and development suggesting activity although to different ends.

The results for "economically sound" are shown in Figure 3. This MDS analysis resulted in three clusters (stress $=.04 ; R^{2}=.99 ;$ distance coefficient $=22.3$ ). The two extreme clusters on Dimension 1 were conservation, environmentalism, and sustainability on the "good" side and pollution and eco-terrorism on the "bad" side. Both of these clusters are low on Dimension 2, which this time seems to reflect economic goodness or activity. Industrial development, although only in the middle of Dimension 1, is very high on Dimension 2.

The MDS analysis for "economically progressive" (see Figure 4) is more difficult to interpret. There are four clusters (stress $=.07 ; R^{2}=.99$; distance coefficient $=26.9$ ). Although in separate clusters, eco-terrorism and pollution are on the "bad" or right side of Dimension 1. Conservation, environmentalism, and sustainability for a cluster on the "good" or left side of Dimension 1; industrial development does the same. This time, however, industrial development is low on Dimension 2, while the conservation cluster is high. If respondents interpreted "economically progressive" as "economically liberal," then Dimension 2 may capture conservation, 
environmentalism, and sustainability as high on this "liberal" dimension while industrial development is low. This interpretation also appears to fit the difference between eco-terrorism, something associated with the radical left, and pollution, which is nearly neutral on this dimension.

Figure 5 portrays the MDS analysis for "environmentally conscious." Once again, there are four clusters (stress $=.03 ; R^{2}=.99$; distance coefficient $=24.11$ ). Dimension 1 appears to reflect environmental "goodness." Although conservation and environmentalism form a cluster that is on the "good" left side, they do not share the cluster with sustainability, which is also on the left side. This time industrial development shares the same side of Dimension 1 as eco-terrorism and pollution. The latter two targets form a loose cluster, a cluster that does not admit industrial development until much later in the analytical hierarchy. This is so even though the distance from pollution to industrial development is much less than it is to eco-terrorism. Dimension 2 appears to reflect active environmental consciousness. Sustainability is higher than conservation and environmentalism, and eco-terrorism is higher than pollution and industrial development. Given that Dimensions 1 and 2 are, by definition, orthogonal, one does not have to assume that sustainability carries some of the negative association attached to eco-terrorism.

The last analysis, "enhances opportunities for future generations," is shown in Figure 6. A four-cluster solution emerged (stress $=.04 ; R^{2}=.99$; distance coefficient $=29.40$ ). Eco-terrorism and pollution share a cluster on the right side of Dimension 1, while conservation and environmentalism share a cluster on the left. Both clusters are near the neutral point for Dimension 2. While industrial development and sustainability are at about the same point along Dimension 1, they are very different on Dimension 2. Industrial development is high on this dimension, while sustainability is low. It appears that industrial development is seen as furthering the opportunities of future generations, while sustainability does not. Even if this interpretation is not correct, the clusters formed in this and earlier analyses indicate that the students do not associate sustainability with economic activity or industrial growth, but with conservation and environmentalism.

\section{DISCUSSION}

How then do the college students who responded to our questions perceive sustainability? Responses to the semantic differential, our more general measure, show that they think sustainability is good, even though not as good as conservation and environmentalism. It is also better than industrial development. Nonetheless, it is not perceived as a particularly robust activity, being less potent than conservation, industrial development, and pollution. It is also the least active of all the concepts we tested. It is thus perceived as a good idea, but one that lacks the vigor and activity found in pollution or industrial development.

Our more specific measures continue this theme. Sustainability is nearly as ethically positive as conservation and environmentalism, but lacks the implied action seen in conservation and, ironically, eco-terrorism. The latter is certainly unethical, but its practitioners are willing to act. Sustainability does much better with the idea of social responsibility. It is perceived as actively and positively socially responsible. Nonetheless, in a society such as the United States where independence is highly valued, this may carry less weight than in a society such as Japan where collective action is valued (Triandis, 1995). Students viewed sustainability, like conservation and environmentalism, as being good, but lacking in economic soundness, while at the same time being progressive. It is as if they were saying that sustainability would be nice, but would run counter to accepted economic principles. Sustainability is certainly seen as environmentally conscious, receiving the highest scores of any of the six items we tested. In light of the low scores for economic soundness, it is an activity that environmentalists might love, but one that is perceived as only marginally congruent with economic activity.

The last and most unexpected responses involved "enhancing opportunities for future generations." Although sustainability is once again a "good" activity, it is perceived as the least likely concept to enhance future opportunities. It was industrial development, not sustainability, which scored highest on the second dimension of the scaling analysis. Sustainability was the lowest of all concepts, lower even than environmentalism and conservation which themselves fell below the neutral point. If other research confirms this observation, it would seem that these 20-year olds view their future as best enhanced by industrial (and one must assume economic) activity, rather than sustaining environmental actions. 
The results of this study raise some important questions for the perception of sustainability. Should proponents of sustainability reporting change the name to one that would be perceived as more powerful? At this stage in the development of sustainability reporting, a name change would probably be counterproductive to promoting the adoption of sustainability reporting. If a name change is not an option, then educating business students (and business persons) about the specific benefits of sustainable practices seems a necessary and appropriate strategy. This education needs to include specific examples of cost savings and increased profits due to sustainable practices. Interface, as with many other companies benefiting from sustainable practices, illustrates how this can be done. Case studies of large and small companies engaged in sustainable practices could be incorporated into accounting and management courses to provide concrete examples. In addition, continuing education courses for management accountants could be another opportunity to give practicing accountants the resources necessary to institute sustainable practices in their companies.

Although sustainability reporting is on the rise, it is not at the level it should be. The results of this paper indicate that proponents of sustainability reporting have a considerable amount of work yet to do. First, the specific benefits of sustainability reporting need to be promoted aggressively within professional organizations (e.g., Institute for Management Accountants, American Institute of Certified Public Accountants). In addition, given both the economic and environmental benefits of sustainability reporting, tax incentives for its use should be instituted. The benefits of waste reduction, increased stakeholder goodwill, and improved environmental, economic, and social performance are only a few associated with sustainability reporting. In addition, the long-term framework of sustainable development offers companies many opportunities to develop new, environmentally sustainable products. These products should help keep the companies on a competitive economic footing within a global context. This should be persuasive to companies that have not yet adopted sustainable development as a major goal. It should also be persuasive to legislators interested in maintaining economic and environmental viability. Finally, to maintain the credibility of sustainability reporting, outside verification of these reports must be instituted. Sustainability reporting offers the dual possibility of economic viability and environmental protection. It has too much potential to not insure that a company's reports of sustainable activity are not accurate.

\section{REFERENCES}

1. $\quad$ Aldenderfer, M. S. \& Blashfield, R. K. (1984). Cluster analysis. Beverly Hills, CA: Sage.

2. Biosolids.com. (2007). Biosolids Basics. Retrieved May 21, 2007 from http://www.biosolids.com/basics.html.

3. Coca-Cola (2005). 2005 Environmental Report. Retrieved May 21, 2007 from www.thecocacolacompany.com/citizenship/environmental_report2005.pdf

4. Corporate Register (2004). Towards transparency: progress on global sustainability reporting 2004. Retrieved May 20, 2007 from http://www.corporateregister.com/pdf/TowardsTransparency.pdf.

5. Fortriede, D. K. (2006). InQsit: Integrated network quizzing, surveying, and interactive testing (Version 10.0). [Computer software]. Muncie, IN: Ball State University.

6. Fritz, B., Keefer, B., \& Nyhan, B. (2004). All the president's spin: George W. Bush, the media, and the truth. New York: Touchstone.

7. Global Reporting Initiative, (2007). Sustainability Reporting Guidelines. Retrieved May 22, 2007 from http://www.globalreporting.org/ReportingFramework/G3Online/.

8. Hardin, G. (1968). The tragedy of the commons. Science, 162, 1243-1248.

9. Interface, Inc. (2007). What is sustainability? Retrieved May 22, 2007 from http://www.interfacesustainability.com/whatis.html.

10. Keller-Rohrback. (2007) Exxon Valdez. Retrieved May 20, 2007 from http://www.seattleclassaction.com/exxon/exxon.asp

11. KPMG (2005). KPMG International Survey of Corporate Responsibility Reporting 2005. KPMG Global Sustainability Services. Retrieved May 18, 2007 from http://www.kpmg.nl/Docs/Corporate_Site/Publicaties/International_Survey_Corporate_Responsibility_200 5.pdf. 
12. KPMG (1999). KPMG International Survey of Environmental Reporting1999. KPMG Environmental Consulting, Retrieved May 16, 2007 from http://ec.europa.eu/employment_social/socdial/csr/060403/kpmgsurvey2005 en.pdf.

13. Laufer, W. (2003). Social accountability and corporate greenwashing. Journal of Business Ethics, 43, 253261.

14. Lizza, R. (2003, February 10). Run on. New Republic, 228 (5), 11-12.

15. Osgood, C. S., May, W. H., \& Miron, M. S. (1975). Cross-cultural universals of affective meaning. Urbana, IL: Illinois.

16. PricewaterhouseCoopers LLP (2004). Discussion with PWC Managing Global Partner Willem Bröcker. The Corporate Responsibility Report, 1,1-3, Retrieved May 16, 2007 from http://www.pwc.com/extweb/pwcpublications.nsf/docid/68143387B9B287ED8525707B004AF55

17. PricewaterhouseCoopers LLP (2002). 2002 Corporate Governance and Sustainability Survey. Retrieved on May 18, 2007 from http://www.pwc.com/fas/pdfs/sustainability\%20survey\%20report.pdf

18. Triandis, H. C. (1995). Individualism and collectivism. Boulder, CO: Westview.

19. White, M. J. \& Li, Y. (1991). Second-language fluency and person perception in China and the United States. Journal of Language and Social Psychology, 10, 99-113.

20. Wikipedia, The Free Encyclopedia. (2007). Eco-terrorism. Retrieved May 10, 2007 from http://en.wikipedia.org/wiki/Eco-terrorism\#Groups

\section{AUTHOR NOTE}

Gwendolen B. White is in the Department of Accounting, Ball State University, Muncie, Indiana, 47306. Mandy J. Cleveland is a doctoral student in the Department of Counseling Psychology, Ball State University, Muncie, Indiana, 47306. Michael J. White is in the Department of Counseling Psychology, Ball State University, Muncie, Indiana, 47306.

Correspondence may be directed to either Gwendolen or Michael White. Email addresses are: 00mjwhite@bsu.edu or gwhite@bsu.edu.

Table 1

Mean Semantic Differential Ratings of Target Concepts

\begin{tabular}{|c|c|c|c|}
\hline \multirow{4}{*}{ Sustainability } & \multicolumn{3}{|c|}{ Dimension } \\
\hline & Evaluation & Potency & Activity \\
\hline & 1.50 & 1.08 & -.03 \\
\hline & (.93) & $(.97)$ & $(.77)$ \\
\hline \multirow[t]{2}{*}{ Conservation } & 2.13 & 1.18 & .06 \\
\hline & $(.85)$ & $(.86)$ & $(.76)$ \\
\hline \multirow[t]{2}{*}{ Environmentalism } & 1.99 & 1.10 & .26 \\
\hline & $(.83)$ & $(.90)$ & $(.82)$ \\
\hline \multirow[t]{2}{*}{ Industrial development } & .56 & 1.19 & .61 \\
\hline & (1.12) & $(.86)$ & (1.04) \\
\hline \multirow[t]{2}{*}{ Pollution } & -2.35 & 1.29 & .30 \\
\hline & $(.89)$ & (1.14) & $(.99)$ \\
\hline \multirow[t]{2}{*}{ Eco-terrorism } & -1.78 & .73 & .43 \\
\hline & $(1.13)$ & $(1.01)$ & $(.84)$ \\
\hline
\end{tabular}

Note. The highest score possible is +3 , while the lowest is -3 . Higher scores are semantically more positive. Standard deviations are in parentheses. 
Figure 1

Multi-Dimensional Scaling Solution for Target Concepts as "Ethical"

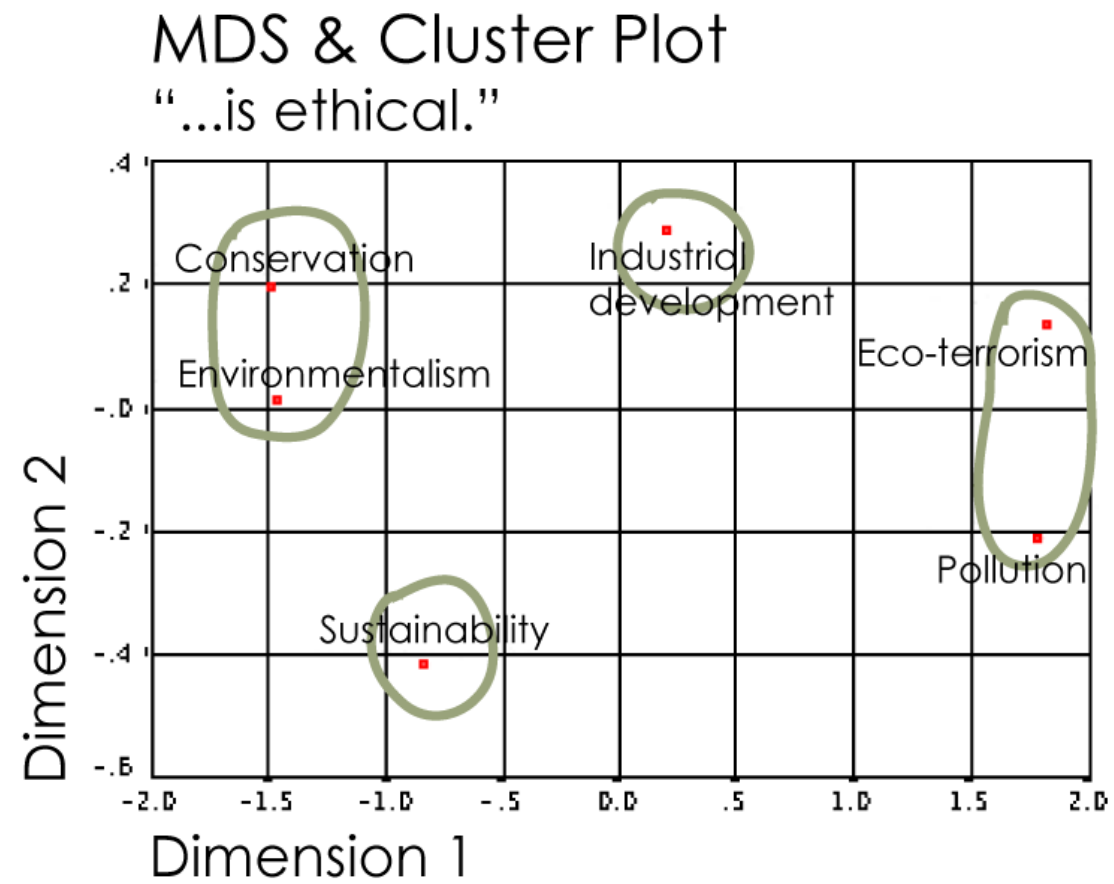

Figure 2

Multi-Dimensional Scaling Solution for Target Concepts as "Socially Responsible"

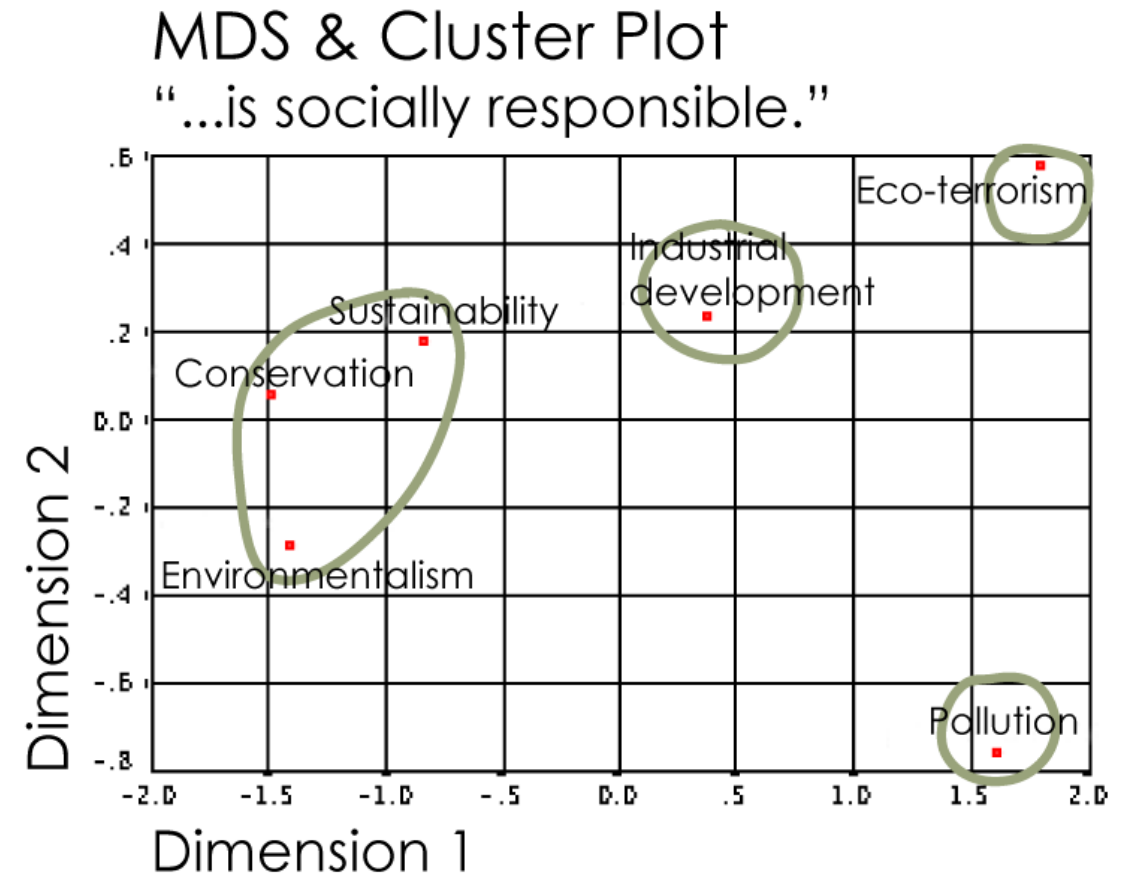


Figure 3

Multi-Dimensional Scaling Solution for Target Concepts as "Economically Sound"

MDS \& Cluster Plot

"...is economically sound."

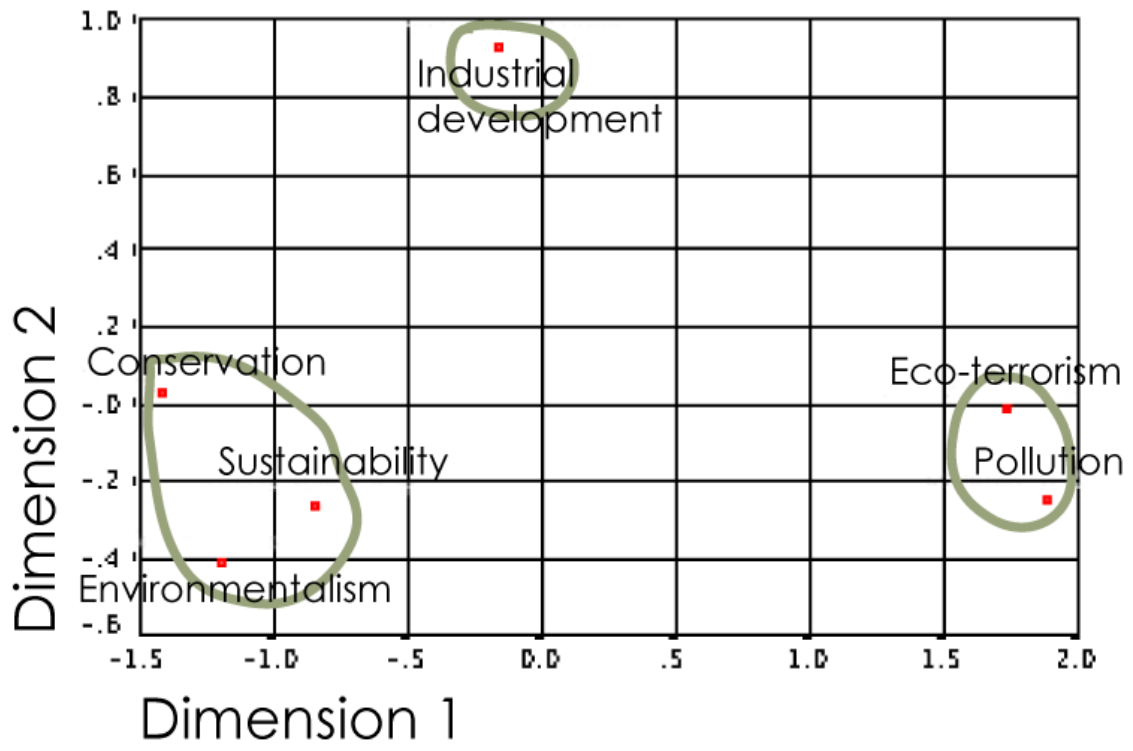

Figure 4

Multi-Dimensional Scaling Solution for Target Concepts as "Economically Progressive"

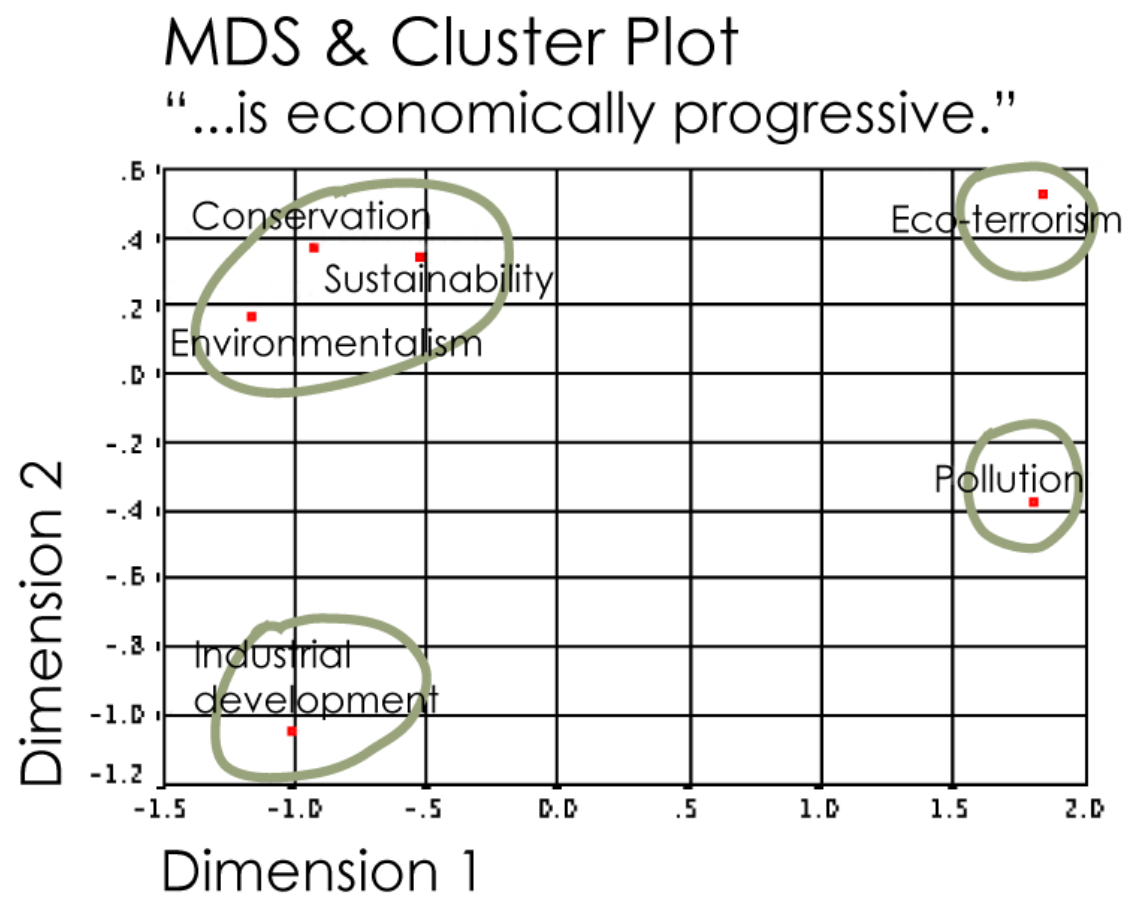


Figure 5

Multi-Dimensional Scaling Solution for Target Concepts as "Environmentally Conscious"

MDS \& Cluster Plot

"...is environmentally conscious."

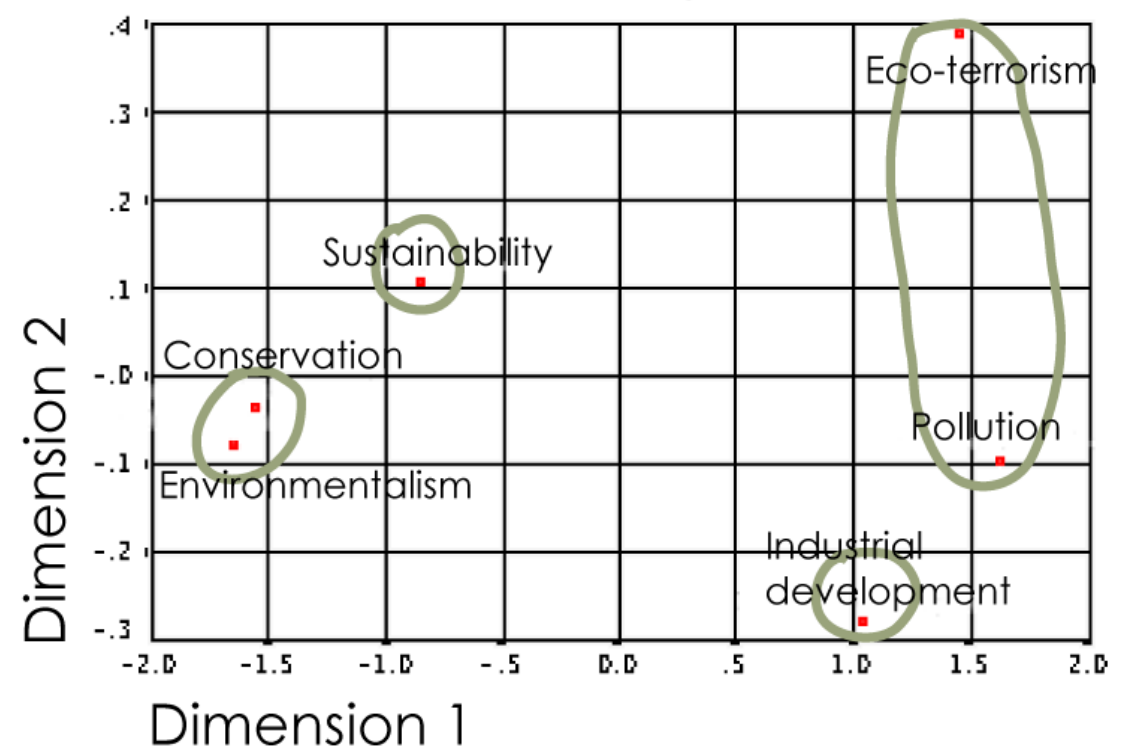

Figure 6

Multi-Dimensional Scaling Solution for Target Concepts as "Enhancing Opportunities"

MDS \& Cluster Plot

"...enhances opportunities for

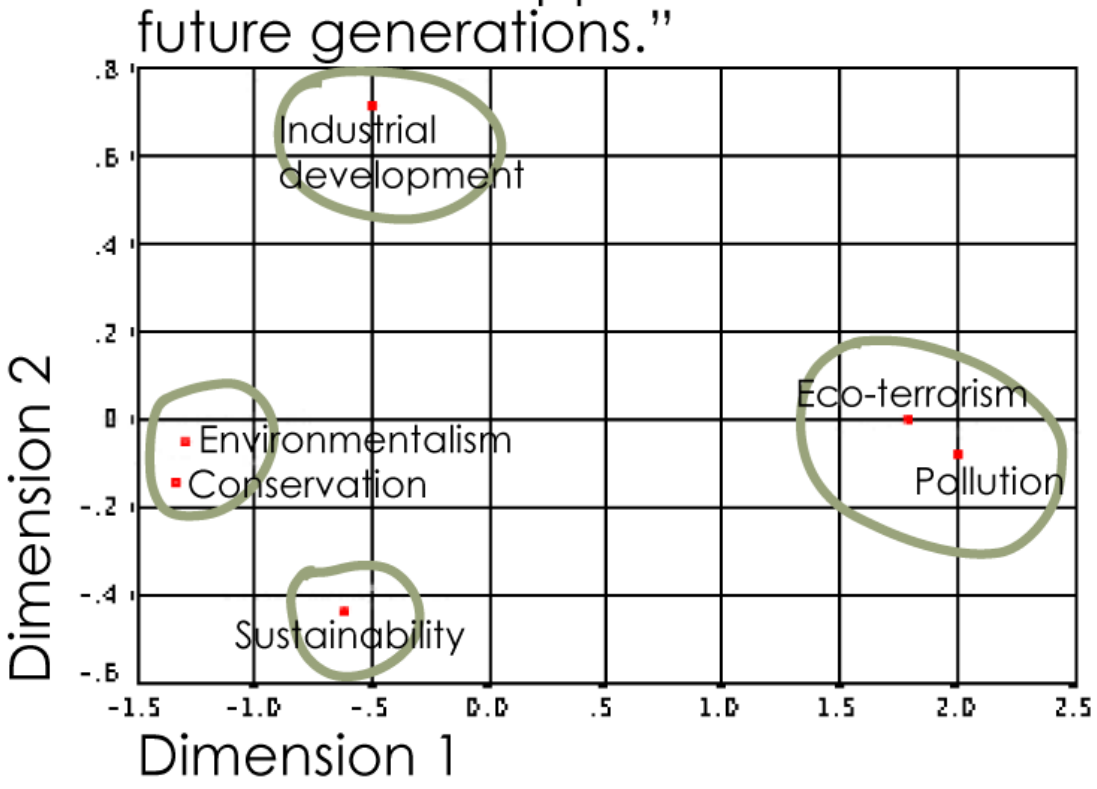


NOTES 